\title{
p53 Expression in three separate tumours from a patient with Li-Fraumeni's syndrome
}

\author{
P King, A W Craft, A J Malcolm
}

\begin{abstract}
The Li-Fraumeni cancer syndrome is a rare autosomal dominant syndrome, characterised by the occurrence of diverse mesenchymal and epithelial neoplasms at multiple sites. It has recently been shown that some of these individuals have a germ line mutation of the p53 tumour suppressor gene. The case of one member of such a family who has now developed three separate primary malignant tumours is reported. All three tumours expressed mutant p53 protein.
\end{abstract}

(F Clin Pathol 1993;46:676-677)

\section{Case report}

The patient belongs to a previously reported "cancer family" (patient III-8 in family A). His mother died of disseminated breast carcinoma at the age of 37 , his brother died at the age of 4 following a subtotal resection of a cerebellar medulloblastoma, and one of his two sisters had an adrenocortical carcinoma resected at the age of 22 months. The other sister is unaffected.

The patient initially presented at the age of 3 years with a hard swelling in his right forearm, which was biopsied. Histological examination showed a cellular tumour composed of bundles of cells with moderately abundant eosinophilic cytoplasm and spindle shaped nuclei with one or two prominent nucleoli. Moderate nuclear pleomorphism was present, and there were scattered mitotic figures. In areas the tumour was less cellular, and there were large ovoid cells with abundant eosinophilic cytoplasm and large vesicular nuclei with prominent nucleoli. Fibrillary material was present in the cytoplasm, and in some this was concentrically arranged around the nucleus. Immunocytochemical staining showed strong positive staining of the tumour cells with antibodies to desmin (Biogenesis) and myoglobin (Amersham). The appearances were those of an embryonal rhabdomyosarcoma (fig 1). An above elbow amputation was performed, and vincristine, actinomycin $\mathrm{D}$, and cyclophosphamide were given for two years.

Twelve years later he presented with a mass in his right fifth rib which was resected. This tumour consisted of lobules of cellular cartilage containing chondrocytes showing nuclear pleomorphism and atypia. Cellularity at the periphery of the tumour was increased. The appearances were those of a chondrosarcoma (grade 2) (fig 2).

Most recently he presented at 20 years of age with a nodule in his scalp. This was resected: histological examination showed islands of cells with amphophilic cytoplasm and spindle shaped nuclei with prominent eosinophilic nucleoli. There was pronounced nuclear pleomorphism and mitotic activity. The overlying epidermis was ulcerated. The tumour cells showed strong positive staining for $\mathrm{S} 100$ protein (Novocastra). The appearances were those of a spindle cell malignant melanoma (fig 3).

Analysis of DNA extracted from blood lymphocytes from this patient has shown the presence of a germ line p53 tumour suppressor gene mutation, with the defect being in the 248 codon $^{2}$ (patient II-4 in family 5). Immunohistochemical staining using Do7 antibody to p53 protein (Novocastra) showed that most nuclei in the rhabdomyosarcoma were strongly positive (fig 4). Many of the nuclei in the melanoma also stained positively. Most of the cells in the more cellular areas of the chondrosarcoma were positive, although very few of the cells in the better dif-

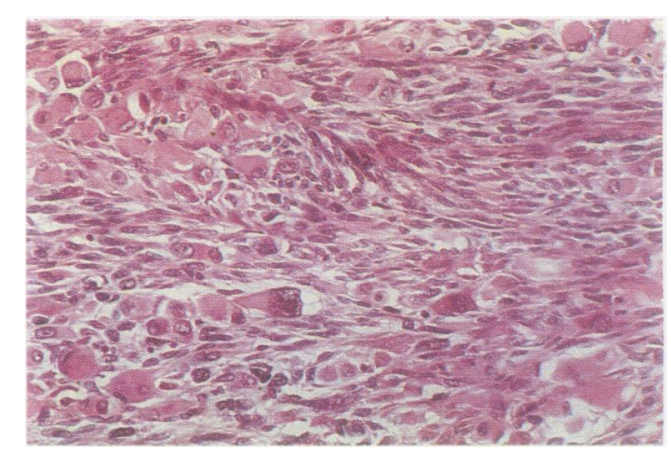

Figure 1 Spindle cell areas intermixed with typical rhabdomyoblasts (haematoxylin and eosin).

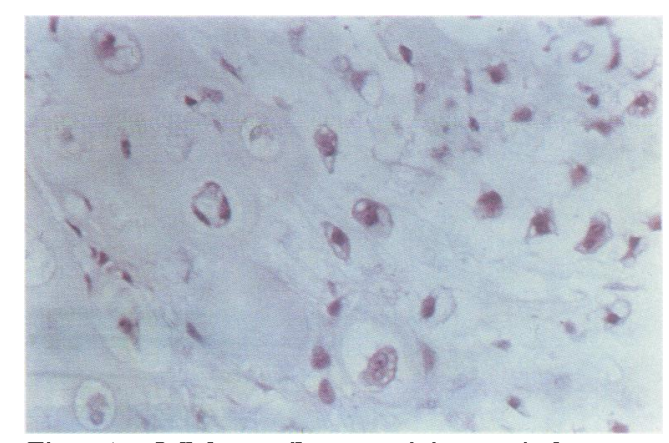

Figure 2 Cellular cartilage containing atypical chondracytes (haemetoxylin and eosin). 


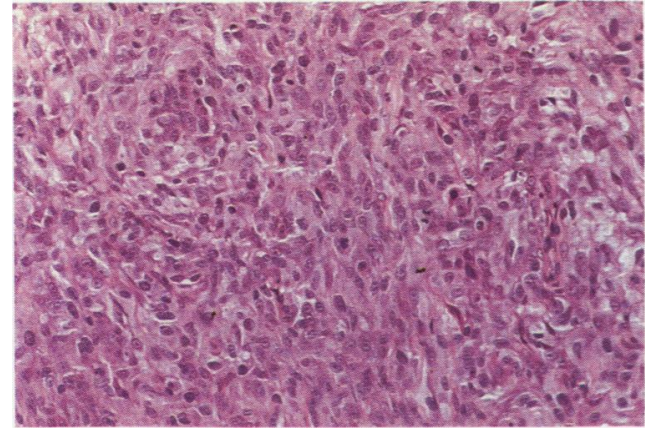

Figure 3 Spindle cells with pleomorphic nuclei and prominent nucleoli (haemetoxylin and eosin).

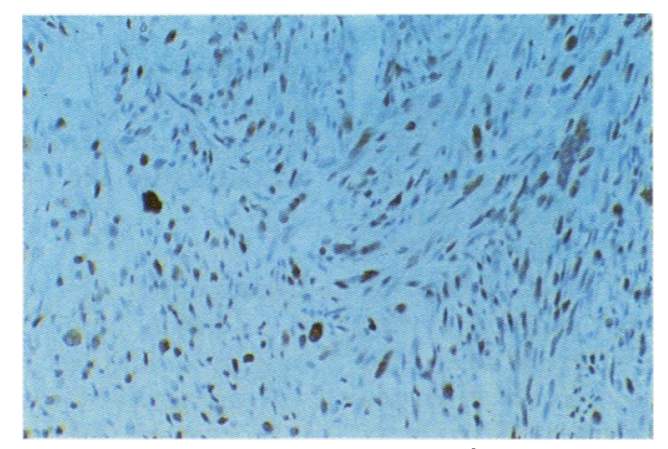

Figure 4 Positive nuclear staining for $p \dot{5} 3$ protein in the rhabdomyosarcoma.

ferentiated parts reacted. Normal cells in tissue adjacent to the three tumours showed no immunoreactivity to $\mathrm{p} 53$ protein using this antibody.

\section{Discussion}

The Li-Fraumeni syndrome was first described in $1969 .{ }^{3}$ It is an autosomal dominant syndrome in which there is a predisposition to a wide variety of neoplasms, including breast and adrenocortical carcinomas, soft tissue sarcomas, brain tumours, osteosarcomas and leukaemia. It has been suggested that melanoma, gonadal germ cell tumours, and carcinomas of the lung, prostate, and pancreas may also be more common in these patients. It has recently been shown that affected members of some of these families have a germ line mutation of the p53 tumour suppressor gene, particularly within exon $7 . .^{25}$ Mutation of p53, followed by a loss of the remaining wild type allele, usually by deletion, is thought to be an important step in cell transformation in a wide range of sporadic neoplasms. ${ }^{6}$ This would explain the propensity of patients with the $\mathrm{Li}$-Fraumeni cancer syndrome to develop multiple tumours, in a manner analogous to that in individuals inheriting a defective retinoblastoma gene. This patient has a germ line mutation of the p53 gene at codon 248, and one assumes that the remaining wild type allele has been lost in each of his three tumours. Positive immunostaining of the tumour cells for mutant p53 protein does not rule out the possibility of additional mutations of the p53 gene occurring at another site, however, and direct sequencing of the tumour DNA would be needed to produce conclusive evidence.

Mutant p53 protein can also inhibit the normal function of wild type $\mathrm{p} 53$ protein. ${ }^{4-6}$ It has been shown that non-malignant cells from patients with the Li-Fraumeni syndrome do not produce excess quantities of mutant p53 protein, such that there is a loss of function effect on the wild type protein. ${ }^{57}$ Hence the non-malignant cells from these patients do not react positively with antibodies to mutant p53 protein using immunohistochemistry. ${ }^{5}$

To our knowledge, the three tumours occurring in this patient are a unique phenomenon. Immunostaining results which show the presence of $\mathrm{p} 53$ protein in the neoplasms of patients with the Li-Fraumeni syndrome have not been reported before. It would be interesting to examine further cases so that it could be established whether immunostaining for $\mathrm{p} 53$ protein in these patients is consistent and whether this carries a poor prognosis, as suggested by $\mathrm{p} 53$ protein expression in other patients.

1 Pearson ADJ, Craft AW, Ratcliffe JM, Birch JM, MorrisJones P, Roberts DF. Two families with the LiFraumeni cancer family syndrome. $f$ Med Genet 1982;19:362-5.

2 Santibanez-Koref M, Birch JM, Hartley AL, et al. p53 germline mutations in Li-Fraumeni syndrome. Lancet 1991;338:1490-1.

$3 \mathrm{Li} \mathrm{FP,} \mathrm{Fraumeni} \mathrm{JF.} \mathrm{Soft} \mathrm{tissue} \mathrm{sarcomas,} \mathrm{breast} \mathrm{cancer}$ and other neoplasms. A familial syndrome? Ann Intern Med 1969;71:747-52.

4 Srivastava S, Zou Z, Pirollo K, Blattner W, Chang EH. Germ line transmission of a mutated p53 gene in a cancer prone family with Li-Fraumeni syndrome. Nature 1990;348:747-9.

5 Malkin D, Li FP, Strong LC, et al. Germ line p53 mutations in a familial syndrome of breast cancer, sarcomas tions in a familial syndrome of breast cancer, sarc
and other neoplasms. Science 1990;250:1233-8.

6 Harris AL. Mutant p53-the commonest genetic abnormality in human cancer? $\mathcal{F}$ Pathol 1990;162:5-6.

7 Srivastava S, Tong YA, Devadas K, et al. Detection of both mutant and wild type p53 protein in normal skin fibroblasts and demonstration of a shared 'second hit' on $\mathrm{p} 53$ in diverse tumours from a cancer prone family with Li-Fraumeni syndrome. Oncogene 1992;7:987-91. 